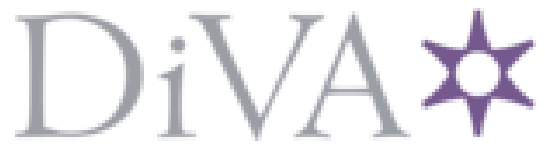

http://www.diva-portal.org

\title{
Postprint
}

This is the accepted version of a paper published in . This paper has been peer-reviewed but does not include the final publisher proof-corrections or journal pagination.

Citation for the original published paper (version of record):

Ekebergh, M., Andersson, N., Eskilsson, C. (2018)

Intertwining of caring and learning in care practices supported by a didacticapproach Nurse Education in Practice, 31(july): 95-100

https://doi.org/10.1016/j.nepr.2018.05.008

Access to the published version may require subscription.

N.B. When citing this work, cite the original published paper.

Permanent link to this version:

http://urn.kb.se/resolve?urn=urn:nbn:se:hb:diva-15341 


\section{Intertwining of caring and learning in care practices supported by a didactic}

approach

\section{Introduction}

The aim in nurse education, is for nursing students to acquire professional competence that is visible in their skills and judgments. This ability is mainly developed during clinical studies when theoretical and practice knowledge encounters the patient's lived experience of health and illness. Learning and caring during clinical studies occur as parallel phenomena, which interact and affect each other. It is important to gain knowledge about how caring and learning interact in clinical contexts. This knowledge has the potential to enhance a fruitful learning support and improve patient care. By studying this interaction, we add insight to the existing body of knowledge. This paper is based on five studies (Andersson, 2015; Eskilsson et al.; 2014; 2015a; 2015b \& 2017), where the interaction between caring and learning in two dedicated educational units (DEUs) has been examined. The studies were included in a research project, with an overall aim to investigate innovative learning environments that can build bridges between theory and practice in nursing education. The project was supported by the university, and it has been carried through in DEUs. Four perspectives were investigated: the students', the patients', the supervisors' and the managers'. The methodology used in the project was phenomenologically grounded in a lifeworld-oriented approach. Data was collected through interviews and observations and then analyzed with a focus on meanings according to Reflective Lifeworld Research (RLR) (Dahlberg et al., 2008). Regarding ethical considerations, the research project was reviewed and approved by the Regional Ethical Review Board of Gothenburg (2011, No 315-11; 2010, No 358-10), and it also followed the 
principles prescribed in World Medical Association Declaration of Helsinki (2013). The research project consisted of five separate studies, four of which were articles (Eskilsson et al., 2014, 2015a, 2015b, 2017), and one which was a monography (Andersson, 2015). The two DEUs have been developed by didactic research, which is the study of learning support in clinical practice (Ekebergh, 2014; Holst \& Hörberg, 2012; Lindahl et al., 2009). The outcomes of this research revealed a certain learning approach and didactic tools, such as supervision models, which have the potential to support both the learning and the caring process developed in the DEU.

\subsection{Background}

The supervisor's role in clinical education is important (Kristoffersson, Mårtensson, Mamhidir \& Löfmark, 2012; Walker et al., 2012) and particularly important for good supervision is a safe and close relationship between the student and supervisor (Higgins \& McCarthy, 2005; Hilli, et al., 2014). Supervising is a multifaceted and responsible mission; therefore it is important to be aware of the need for an educational preparation programme and a supervision support community for nurse supervisors/mentors (Ekebergh, 2011; Sandvik et al., 2012). It is also important that there are learning and caring environments that can provide students with suitable prerequisites for learning (Lindahl et al., 2009; Moscato, et al., 2007; Ekebergh, 2014). Supervision can be strengthened with the help of various didactic strategies, for example, group supervision (Arvidsson et al., 2008) or peer supervision (Holst \& Horberg, 2012). Having possibilities for reflection during the clinical studies is also essential for students' learning (Ekebergh, 2007; 2009; Sandvik et al, 2014). A patient's health condition and situation is central to the students' learning process. They need to link the patient's experiences to a theoretical framework in order to develop a deeper understanding for how to care for the patient. Therefore, it is crucial for students to create a trusting relationship with the patient. (Munukka, et al., 2002; Suikkala \& Leino-Kilpi, 2005; 2008). Research shows that patients often have 
positive experiences when they know they are actively participating in students' learning processes (Mossop \& Wilkinsson, 2006; Stockhausen, 2009; Towle et al, 2010), and they are also concerned about students' training to become future qualified nurses (Forrest et al., 2000). Debyser et al. (2011) found that patients' involvement in the students' learning process could support a more holistic view of the human being, and that patients also develop strength through their participation. There is however a potential vulnerability for both the patient and the student (Lauckner et al., 2012), and it is therefore important to develop an atmosphere that can support a learning relationship (Manninen et al., 2014). Consequently, it is advantageous to consider the patient as an integral part of the learning process (Towle et al., 2010; 2011; Perry et al., 2013; Scammel et al., 2016). Stockhausen (2005) emphasized the importance of authentic encounters to learn the art of caring in nurse education and commented on the significance of further research on patients' involvement in students' learning.

Overall, the literature shows a significant amount of studies focused on teaching and learning in clinical practice. The student's or the supervisor's perspective is particular illuminated in the research, but there are also studies concerning the patient's perspective in the learning process. However, there are a lack of studies that explicate caring and learning as an intertwined process. Caring and learning take place simultaneously in an interconnected manner, and from an educational perspective these can be perceived as an intertwined phenomenon. This perspective on the learning and caring processes in learning environments might contribute to the understanding of learning and caring in a DEU.

The interaction between caring and learning has been investigated in two different educational wards: one for psychiatric care and one for orthopedic care. The aim was to create an awareness of caring and learning as intertwined phenomena and when and how they converge in meetings between students and patients (Andersson, 2015; Eskilsson et al 2014, 2015a, 2015b, 2017). This paper is based on the outcomes of these two studies. 


\subsection{Research design}

An analysis of the outcomes of the studies mentioned above (Andersson, 2015; Eskilsson et al 2014, 2015a, 2015b, 2017) has been performed in the present study. This analysis is based on a Reflective Lifeworld Research (RLR) approach (Dahlberg et al 2008) which is grounded in a lifeworld-oriented phenomenology (Husserl, 1973, 1978) that focuses on meaning, openness and a reflective attitude. RLR was also applied in the original project and the studies by Andersson and Eskilsson to investigate and describe the lived experiences of learning and caring from the perspectives of the supervisors and patients. Ethical issues were considered in the same way as in the original project (see introduction). A lifeworld-oriented approach includes a reflective attitude and an approach of openness, which enables the student to reach a meaningful level in the analysis. It was important to look beyond prejudices and assumptions to reach a deeper understanding of the studied phenomena. Therefore, we preferred this analysis approach which has a stable epistemological base.

The analysis in the present study consisted of a reflective rigorous procedure to search for meaning and significance for the outcomes of the two studies in accordance with RLR. The analysis has resulted in a synthesis, which can be understood as an abstraction of the two outcomes, or as a general structure (Lindberg et al. 2016) that describes the interaction, between caring and learning on an educational ward. In the presentation of the results in this paper, there are some quotes that firmly establish the findings and make the results more transparent.

The next step in the present study was to examine the synthesis regarding learning support. In a scrutinized procedure and inspired of a lifeworld didactic perspective (Ekebergh, 2007; 2011) we searched for themes for a didactic method that can support the convergence and intertwining of caring and learning. Consequently the result consists of both a synthesis and a didactic 
method. The first part of the result, presented below, is the synthesis. After that follows the didactic method.

\section{Results}

There is an interaction between caring and learning on a DEU that affects and unites the two aspects. The encounters between the students and the patients need to have a trusting nature in order for caring and learning to be enriched by each other. These encounters are characterized by an active interaction in which the patient talks about his illness and the student listens attentively and asks questions. The patient and the student will thus be involved in each other's worlds, the patient's world is characterized by vulnerability and a sense of homelessness due to illness, and the student's world consists of longing and needs for learning and understanding in order to be able to grasp the nurse's work. For example, a student in the psychiatric DEU expressed, "You get a real and lived picture of the illness. The patient's experiences is something totally different, that you cannot read in [a] book". A patient in the same DEU said, "By telling my story to the student, I get the opportunity to clarify the illness and my problems to myself. I have to reflect over my existence and myself ". The patient's voice is heard and in a joint reflection with the student about illness and health development a mutual learning can occur. The student and the patient have a common desire to understand how health can best be achieved and in optimal meetings both show responsibility for and care for each other, which requires security, solidarity and a sense of companionship. A student in the psychiatric DEU showed her strong will to understand the patient's world and to create a trustful relationship: "I thought that I must do something. I want to learn. I don't want to merely be inactive in the staff room in eight weeks, so I contacted the patient by myself and we had a dialogue, without a supervisor". In order to create meetings of a genuine 
nature a mutual invitation by both parties is required in which they make themselves available to each other. In these genuine encounters, which can be understood as genuine interpersonal meetings with professional overtones, is it possible for caring and learning to converge and an intertwining to take place, a unit is formed, which is more than just caring and learning separately. When they converge and intertwine they are strengthened and developed by each other and cannot be distinguished as separate components. This is an active process in which students take an active role in the patient's health development and their own development of understanding: "That's when I learn, when I'm caring, then I learn both how to approach the patient and the practical skills. I have to have a patient so that I can learn how I'm supposed to do it" (student in the orthopaedic DEU). The patient participates actively in both his/her health process and the student's learning process, An intertwining caring and learning process strengthens the patients' health processes and the students' development of understanding of the caring context, which is the optimum for both the patient and the student. For example, one patient in the psychiatric DEU said, "I help them to a better learning at the same time as I try to get health and wellbeing". To quote another student from the same DEU: "You learn a lot [when you $]. .$. listen to the patients and hear their experiences".

The supervisor's experiences, education and ability for reflective approach play a significant role in order for these meetings to take place. It is the supervisor who can create opportunities for meetings between the patient and the student as well as guide the interaction and thus pave the way for the convergence. The challenge is to guide in such a manner so that genuine meetings between patients and students are realized, which among others means caring at a distance via the student, and laying the foundation for a caring and learning companionship. The student happily assumes the challenge to care if these conditions exist. A competition arises between them when caring and learning are separated and polarized, which leads to 
disorientation and loneliness among both students and patients. Supervisors can counteract this separation and instead strengthen the interweaving.

An important prerequisite in order for caring and learning to converge and intertwine at DEU is that healthcare managers take responsibility for enabling the type of environment necessary for the convergence. An emphasis on taking responsibility and not just having responsibility is fundamental here. The managers are dependent on qualified supervisors and a close and effective cooperation with the nursing school at the university to fulfill its responsibilities.

To strengthen and promote the intertwining of caring and learning requires a well-developed cooperation between the nursing school and the healthcare organization. A consensus regarding both the educational mission and the meaning of caring and learning is necessary. Both the nursing school and the healthcare organization need to take responsibility for conscious strategies that enable the convergence of caring and learning.

\subsection{Didactic method}

In this context, the term didactic means to support learning, and a didactic method, which also can be understood as didactic activities, consists of learning supports or strategies, such as supervision. A didactic method can consist of teaching activities or it can take the role of a framework for learning support (Ekebergh, 2001; 2005). The method which was developed in this study is not described in terms of specific activities, but as a thought out structure for supervision and learning that can enable the convergence of caring and learning.

The method consists of three themes: Genuine meetings - Sensitivity for the patient's story Refection in interaction. These themes represent tools in the supervision for supporting caring and learning to converge and intertwine. They can be adapted to different caring and learning contexts. 


\subsubsection{Genuine meetings}

The core of the didactic method is to bring about genuine meetings, which are characterized by trust and consideration as well as security and sensitivity for all involved. Students need support from supervisors in creating trust towards the patient and in daring to "go near" in the meeting so that an active interaction between the student and the patient takes place. The student should take an active role in the patient's health process and in the development of their own understanding. The patient is active in both his/her own health process, and the student's learning process. When trust is established both parties can mutually invite the other and thus be available for each other. The student provides the patient with care and the patient offers the student the opportunity to learn. Supervisors and health teams initiate and create the conditions for genuine meetings. It is assumed that they can approach the patient's as well as the student's lifeworld in a tactful way, so that they get to know them. They can then make plan and assess the meetings that enable caring and learning to converge. The common theme in the supervision is the student's caring abilities and learning needs which are matched with the patient's health care needs. This process is ongoing throughout the clinical studies.

The supervisors have individual conversations with students before and during the clinical studies. The focus in these conversations is how caring and learning should converge and intertwine in the student's learning process and ensure good patient care. Similarly, the supervisor talks with the patients about care needs and expectations. Both the individual and general learning objectives for the current level of education and the planning of the actual patient care are included in the preparation for genuine meetings.

\subsubsection{Sensitivity for the patient's story}


It is also important to stimulate a focused listening of the patient's story about how it is to live with illness and disease. This concerns triggering a curiosity to learn more about the illness and the patient's perspective, and to develop a genuine willingness to listen to the patient's story. The student's questions initiate a mutual reflection in the conversation with the patient. The dialogue aims to make the patient's health be visible with a focus on the patient's experience and providing the conditions for caring that can enable well-being. In this form of dialogue the patients will be confirmed in their experiences of illness, which strengthens the health process. In the conversation the student applies the theoretical knowledge of disease and illness linked to the patient's health experiences and leads the conversation in such a way that the patient's lived experiences provide a development and deepening of this knowledge. In this way, the interweaving of theory and lived experience will be realized, which deepened during the reflection with the supervisors after the completion of the meeting. The patients also take advantage of this link between theory and lived reality, which gives them knowledge and learning about their disease and illness. The subsequent reflection is particularly important where the students get the opportunity to clarify ambiguities and consider all aspects of the patient's story in relation to the theory. This reflection also includes evaluating and planning new caring activities. The students learn from their own experiences in this procedure, about what it is like to receive the patient's story and to manage to be in a dialogue with the patient, which supports an embodied caring and learning.

\subsubsection{Reflection in interaction}

Reflection is the hub of the interaction between the patient, the student and the supervisor and supports each person's learning and the care of the patient. The interaction is characterized by "a reflective approach", an inquiring attitude, which is gradually developed by the student's 
uncertainty and leads to questions being asked and answers sought, which triggers focused listening.

The student's care for the patient stimulates both caring and learning in the interaction. The patient's considerations of the student are visible through active involvement in the student's learning. However, thoughtfulness and a conscious reflection are required if caring and learning are to converge and be intertwined. A prerequisite is that the students have the knowledge about what reflection actually is and that they have been trained to use reflection in the learning processes

The supervision of students is done both close at hand and at a distance and they should have the possibility to act independently in the care and to practice to "stand on their own two feet." In a reflective supervision, the student receives support both prior to meetings with patients and caring activities, and after the meetings in a monitoring session. The supervisors need to constantly develop the ability to care at a distance, which entails trusting the student and handing over the caring responsibility in some meetings and caring sequences. This responsibility and trust is then returned to the supervisor in the monitoring session.

Reflection occurs continuously like a common theme of conversation between the patient, the supervisor and the student, but reflection can also be organized in special sessions such as group reflection where the care team, together with the supervisor and students, as well as patients, are involved. Group reflection can promote a conscious convergence of caring and learning by more questions and thoughts being woven into reflection, which increases the possibilities for a deeper intertwining. Reflection can also be carried out by the writing of diaries, which both the student and the patient can do prior to having reflective conversations about each other's diaries. Furthermore, reflection sessions can occur in care planning and nursing conferences where the patients can participate and give their story. 


\section{Discussion}

This research has been conducted with a reflective lifeworld approach, RLR, (Dahlberg et al. 2008), which has facilitated, on the basis of two studies, the gaining of a deeper understanding of how and when caring and learning converge and intertwine in the learning and caring processes. Other methodological approaches would have been possible to use, but the reflective procedure of searching for meanings, that characterizes RLR, has revealed essential meanings that give us a clearer picture of caring and learning as intertwined. This research approach has been applied and been successful in several caring science and caring didactic studies (eg. Carlsson et al, 2005; Almerud et al., 2007; Dahlberg \& Ekebergh, 2008, Johansson et al., 2009; Ekebergh, 2011; Larsson et al ., 2013; Holst \& Horberg, 2012, Lindberg, et al., 2013; Berglund, 2014). The RLR approach is an advanced method that requires a strict bridling approach, which does not take anything for granted in the analytical process, and where every meaning unit is closely examined and questioned with openness. RLR has also been used in the two studies whose results have been analyzed and it was thus an advantage to use this research approach in the present analysis.

The study shows that genuine meetings are a prerequisite for caring and learning to converge. This particular aspect is therefore the hub of the didactic method. The challenge for the supervisor is to provide the conditions for these meetings, but students should also be active in generating encounters with patients. A key aspect that occurs is the patient's safety and security, which should have priority in these meetings, however the student's safety should of course also weigh heavily. It is possible that competition between them could occur, which has been highlighted in research on supervision (Ekebergh, 2001; 2009; Manninen, Henriksson Scheja, \& Silén, 2015). Overall research shows the importance of the supervisor's knowledge of the 
student's abilities and the patient's needs and perspective on his/her illness and treatment. It is also important that the supervisor has the trust of the patient in the care. Hilli, et al (2014) maintain that the ethical dimension is crucial for good supervision.

There should be a progression in both learning and caring during the clinical studies. This development can probably best be guided and enabled by the supervisor in reflective conversations with both patients and students prior to meetings and caring activities and also in follow-up reflections after the completed caring activities.

The students' tools in the meeting with the patients are conversation or dialogue, in which the patient's story initiates a mutual reflection. The present study shows this reciprocity of reflection and learning, which has not been identified in the previous research. The student's questions start the patient's reflection and the student's reflection is triggered by the patient's response and experiences. It is important that students have a listening approach to support the patient's learning, thus also becoming caring and promoting health (Berglund, 2014; Ekebergh, 2014). Sandvik et al (2013) develop this aspect and emphasize the need for a caring relationship for effective learning and caring during a clinical placement.

In order for the conversation to be developed in this way and to allow a convergence of caring and learning, it is required that students have both a good theoretical knowledge about conversations with patients and have practiced this prior to clinical studies. Students can generally feel insecure about clinical placements (Sharif \& Masoumi, 2005; Kragelund, 2011). Berglund et al (2012) and Ekebergh $(2009,2011)$ show that students can find it difficult to initiate and pursue discussions with patients. These studies show the importance of students being properly prepared for this task. They should also have knowledge of what reflection is and how reflection works. From this it can be concluded that students need to have trained conversations or simulated conversations in clinical training centers or similar places prior to a 
clinical placement, as well as practicing reflection in reflection seminars during the theoretical section. This is of crucial importance for the students to get the most out of the real meeting with the patient (Bulman, Lathlean, \& Gobbi, 2012; Knutsson et al., 2015).

The didactic method developed in this study can be understood as a conscious structure that can support supervision and learning and provide conditions for caring and learning to converge. A didactic method does not work if it is not integrated in the care given by the healthcare services. A prerequisite for integration is that the supervisor and the healthcare team plan the learning process and the caring process as a cohesive unit. They need good forward planning and a tactical alertness to see the opportunities for genuine meetings that students can be led into in a sensitive way. Furthermore, they must have a reflective approach for supporting the learning and caring processes and promoting a progression in these processes. Another condition is that the nursing school and healthcare services interact during the student's clinical studies. The presence of clinical teachers, who can support the supervisors and the care team in the planning and implementation of a reflected caring and learning is a necessity. Teachers and lecturers are also an important support for students during the clinical studies. It is essential that there is a consensus about what good care and a good learning support means by all involved (Seshan, Ramasubramanium, Noronha \& Muliira, 2010). Care managers are also important for the implementation of this didactic method. They first need to have an effective cooperation with the nursing school, and furthermore, they should be able to contribute with the organizational resources and conditions required for the supervisors and care teams to be able to apply the method. The importance of a partnership between the academic and the clinical organizations has been highlighted in the literature. A close collaboration and a shared philosophy is beneficial for both the clinic and the university (Glazer et al., 2011; Hinic et al., 2017). A partnership also has the potential to close the gap between theory and practice (Huston et al., 2018). 
Previous research has shown that when the nursing schools and the healthcare services cooperate in a constructive manner, good conditions for the implementation of new didactics and supervisions models in clinical studies are created, even if it is difficult work (Ekebergh, 2013, 2011; Ekebergh \& Määtte, 2005; Lindahl, Dagborn \& Nilsson, 2009; Holst \& Horberg, 2012; Moscato, Miller, Logsdon, Weinberg, \& Chorpenning, 2007).

The implementation of the didactic approach in the healthcare services should be based on local and current conditions. It is in the application of the method that the latter will be concretized by creating forms of supervision and learning that are relevant and appropriate for current conditions and situations. The main fact should be that the method themes, genuine meetings, sensitivity for the patient's story and reflection in interaction, are reflected in the healthcare practice. Previous research has shown that an overly dominant method can be a barrier to learning (Ekebergh, 2005), which in this case would entail that it does not support the intertwining. A didactic approach must instead be a powerful tool and aid for all parties involved in caring and learning.

\section{Conclusions}

When caring and learning are clearly intertwined phenomena, caring as well as learning are improved in caring practice. Patients, supervisors and managers constitute in this case a major resource for improving the quality of practical education and of care. Furthermore, students play an integral role in caring for the patients' well-being and the supervisors' development. It should thus be in the interests of both the nursing schools and the healthcare services to strengthen this intertwining. Specifically, it may concern a joint development of supervision models that have this stated purpose and focus. One example is the didactic method developed in this study. This didactic method, with its themes; Genuine meetings - Sensitivity for the 
patient's story - Reflection in interaction, creates a thought out structure that provides the conditions for caring and learning to converge and intertwine.

\section{Acknowledgements}

The authors would like to thank all participants in the original studies this paper is based on.

\section{References}

Almerud, S., Alapack, J., R., Fridlund, B. \& Ekebergh, M. (2007). Of vigilance and invisibility - being a patient in technologically intense environments. Nursing in Critical Care, 12, 3, 151 - 158. Doi: https://doi.org/10.1111/j.1478-5153.2007.00216.x

Andersson, N. (2015). När vårdande och lärande sammanfaller: patienters, studenters och handledares erfarenheter av möten på en utbildningsvårdavdelning inom psykiatrisk vård /When caring and learning converge. Patients', students', and supervisors' experiences of encounters in a dedicated education unit within psychiatric care]. Doctoral Thesis.(Vol. 212/2015). Växjö: Linnaeus University Press.

Arvidsson, B., Skärsäter, I., Fridlund, B., Svensson, M-L. \& Baigi, A. (2008). Effects of process oriented group supervision as reported by nursing students. Vård I Norden. 28. (1). $26-29$

Berglund.M., Sjögren, R, \& Ekebergh, M. (2012). Reflect and learn together - when two supervisors interact in the learning process of nurse education. Journal of Nursing Management, 20, $152-158$.

Berglund, M. (2014). Learning turning points in life with long-term illness - visualised with the help of the life-world philosophy. International Journal Qualitative Studies on HealthWell-being,9: p. 22842 Doi: https://dx.doi.org/10.3402\%2Fqhw.v9.22842

Bulman, C., Lathlean, J., \& Gobbi, M. (2012). The concept of reflection in nursing: Qualitative findings on student and teacher perspectives. Nurse Education Today, 32(5), e8e13. Doi: https://doi.org/10.1016/j.nedt.2011.10.007

Carlsson, G., Dahlberg, K., Dahlberg, H. \& Ekebergh, M. (2005). Patients longing for authentic personal care: A phenomenological study of violent encounters in psychiatric settings. Issues in Mental Health Nursing, 27, 3, 287 - 305.

Dahlberg, K. \& Ekebergh, M (2008). To use a method without being ruled by it: Learning supported by drama in the integration of theory with healthcare Practice. The Indo-Pacific Journal of Phenomenology, volume 8, special edition. 1 - 20.

Dahlberg, K.,Dahlberg, H. \& Nyström, M.(2008). Reflective Lifeworld Research. Studentlitteratur: Lund. 
Debyser, B., Grypdonck, M. H. F., Defloor, T., \& Verhaeghe, S. T. L. (2011). Involvement of inpatient mental health clients in the practical training and assessment of mental health nursing students: Can it benefit clients and students? Nurse Education Today, 31(2), 198-203. Doi: http://dx.doi.org/10.1016/j.nedt.2010.06.001

Ekebergh, M. (2001). Tillägnandet av vårdvetenskaplig kunskap - reflexionens betydelse för lärandet. [The acquisition of caring science in nursing and nursing education - the importance of reflection for learning]. Doctoral thesis. Institutionen för Vårdvetenskap, Åbo Akademi: Vasa.

Ekebergh, M. \& Määttä, S. (2005). Lärandet på en utbildningsvårdavdelning - att sammanbinda vårdvetenskaplig teori med vårdpraxis. [The learning in a dedicated educational unit - to intertwined caring science theory with caring practice]. Forskningsrapport. Institutionen för Vårdvetenskap, Högskolan i Borås Rapport nr 1.

Ekebergh, M. (2005). Are you in control of the method or is the method in control of you? Nurse Educator, 30, 6, 259 - 262

Ekebergh, M. (2007). Lifeworld-based reflection and learning: a contribution to the reflective practice in nursing and nursing education. Reflective Practice 8, 3, $331-343$.

Ekebergh, M. (2009). Developing a Didactic Method that Emphasizes Lifeworld as a basis for learning. Reflective Practice, Special Issue 10(1), 51 - 63.

Ekebergh, M. (2011). A Learning Model for Nursing Students during Clinical Studies. Nurse Education in Practice, 11, $384-389$

Ekebergh, M. (2014). Dedicated Educational Unite: A Scandinavian Model. In Edgecombe, K. \& Bowden, M (Edt.), Clinical learning and teaching innovations in nursing: dedicated educational units building a better future. (pages 123 -130). Springer: Dordrecht.

Eskilsson, C., Hörberg, U., Ekebergh, M. \& Carlsson, G. (2014). Student nurses' experiences of how caring and learning is intertwined - A phenomenological study. Journal of Nursing Education and Practice, 4(2), 82-93. doi:10.5430/jnep.v4n2p82

Eskilsson, C., Carlsson, G., Ekebergh, M., \& Hörberg, U. (2015 a). The experiences of patients receiving care from nursing students at a Dedicated Education Unit: A phenomenological study. Nurse Education in Practice, 15(5), 353-358. doi:http://dx.doi.org/10.1016/j.nepr.2015.04.001

Eskilsson, C., Hörberg, U., Ekebergh, M., Lindberg, E.,\& Carlsson, G. (2015 b). Caring and learning intertwined in supervision at a dedicated education unit - a phenomenological study. Reflective 1-12. doi:10.1080/14623943.2015.1095726

Eskilsson, C., Lindberg, E., Carlsson, G., Ekebergh, M., \& Hörberg, U. (2017). Manager's responsibility to support caring and learning in clinical education units. Clinical Nursing Studies, 5 (3) https://doi.org/10.5430/cns.v5n3p34 
Forrest, S., Risk, I., Masters, H. \& Brown, N. (2000). Mental health service user involvement in nurse education: exploring the issues. Journal of psychiatric and mental health nursing, 7, (1). 51 - 57. Doi: 10.1046/j.1365 - 2850.2000.00262.x

Glazer, G., Erickson, J-I., Mylott, L., Mulready-Shick, J-A. \& Bannister, G. (2011). Partnering and Leadership. Core Requirements for Developing a Dedicated Education Unit. The Journal Nursing Administration. Vol. 41 Number 10, pp 401-406 https://doi.org/10.1097/NNA.0b013e31822edd79

Higgins, A. \& McCarthy, M. (2005). Psychiatric nursing students' experiences of having a mentor during their first practice placement: an Irish perspective. Nurse Education in Practice, 5, (4), 218 - 224. Doi: https://doi.org/10.1016/j.nepr.2004.12.002

Hilli. Y., Salmu,M. \& Jonsén E. (2014). Perspectives on good preceptorship: A matter of ethics. Nursing Ethics, 21:565-75. https://doi.org/10.1177/0969733013511361

Hinic, K., Kowalski, M. \& Silverstein, W. (2017) Professor in Residence: An Innovative Academic-Practice Partnership. Journal of Continuing Education in Nursing ( $\mathrm{J}$ CONTIN EDUC NURS), Dec2017; 48(12): 552-556 https://doi.org/10.3928/00220124-20171115-06 .

Holst, H. \& Hörberg, U. (2012) Students' learning in an encounter with patients - supervised I pairs of students. Reflective Practice 13, 693 - 708. Doi: http://dx.doi.org/10.1080/14623943.2012.670623

Husserl, E. (1973). Experiences and judgment: investigations in a genealogy of logic. Northwestern University studies of phenomenology and existential philosophy. Evanston: North Western University Press.

Husserl, E. (1978). The crisis of European sciences and transcendental phenomenology: an introduction to phenomenological philosophy. Northwestern University studies of phenomenology and existential philosophy. Evanston: North Western University Press.

Huston, C. L., Phillips, B., Jeffries, P., Todero, C., Rich, J., Knecht, P., . . Lewis, M. P. (2018). The academic-practice gap: Strategies for an enduring problem. Nursing Forum, 53(1), 27-34. https://doi.org/10.1111/nuf.12216

Johansson, K. Ekebergh, M. Dahlberg, K. (2009). A lifeworld phenomenological study of the experience of falling ill with diabetes. International Journal of Nursing Studies 46, 197 - 203. Doi: https://doi.org/10.1016/j.ijnurstu.2008.09.001

Knutsson, S., Jarling, A., \& Thorén, A-B. (2015). "It has given me tools to meet patients' needs": students' experiences of learning caring science in reflection seminars. Reflective practice, 1-13. Doi: 10.1080/14623943.2015.1053445

Kragelund, L. (2011). Student nurses' learning processes in interaction with psychiatric patients: A qualitative investigation. Nurse education in practice. 11, (4), Doi: https://doi.org/10.1016/j.nepr.2010.11.019

Kristoffersson, M-L., Mårtensson, G., Mamhidir, A-G. \& Löfmark, A. (2012). Nursing students' perceptions of clinical supervision: The contributions of preceptors, head preceptors and clinical lecturers. Nurse Education Today, 33, (10). 1252 1257. Doi: https://doi.org/10.1016/j.nedt.2012.08.017 
Larsson, M., Johansson Sundler, A.\& Ekebergh, M. (2013). Beyond Self-Rated health: The Adolescent Girl's Lived Experiences of Health in Sweden. The journal of School Nursing, 29(1), 71 - 79. Doi: 10.1177/1059840512446151

Lauckner, H., Doucet, S., \& Wells, S. (2012). Patients as educators: the challenges and benefits of sharing experiences with students. Medical Education, 46(10), 992-1000. Doi:10.1111/j.1365-2923.2012.04356.x

Lindahl, B., Dagborn, K. \& Nilsson, M. (2009). A student-centered clinical educational unit description of a reflective learning model. Nurse Education in Practice 9, 5 - 12. Doi: https://doi.org/10.1016/j.nepr.2008.03.008

Lindberg, E., Hörberg, U., Persson, E. \& Ekebergh, M. (2013). It made me feel human. A phenomenological study on older patients' experiences of participating in a team meeting. International Journal of Qualitative Studies on Health and Well-being, 8, 1 - 10. Doi: https://doi.org/10.3402/qhw.v8i0.20714

Lindberg, E., Österberg, A., S. \& Hörberg, U. (2016). Methodological support for the further abstraction of and philosophical examination of empirical findings in the context of caring science. International Journal of Qualitative Studies on Health and Wellbeing, 11: 30482. Doi: https://dx.doi.org/10.3402\%2Fqhw.v11.30482

Manninen, K., Henriksson, E. W., Scheja, M., \& Silén, C. (2014). Patients' approaches to students' learning at a clinical education ward-an ethnographic study. BMC Medical Education, 14, 131. Doi:http://dx.doi.org/10.1186/1472-6920-14-131

Manninen, K., Henriksson, E., Scheja, M., \& Silén, C. (2015). Supervisors' pedagogical role at a clinical education ward - an ethnographic study. BMC Nursing, 14(1), 1-8. Doi: https://doi.org/10.1186/1472-6920-14-131

Moscato, S. R., Miller, J., Logsdon, K., Weinberg, S., \& Chorpenning, L. (2007). Dedicated education unit: An innovative clinical partner education model. Nursing Outlook, 55(1), 31-37. Doi: https://doi.org/10.1016/j.outlook.2006.11.001

Mossop, M. \& Wilkenson, T. (2006). Nursing education in gerontological clinical settings: What do elderly patients think of student-renered care? Journal of Gerontological Nursing 32, (6). 49 - 55

Munukka, T., Pukuri, T., Linnainmaa, P \& Kilkku, N. (2002). Integrating of theory and practice in learning mental health nursing. Journal of Psychiatric and Mental Health Nursing. 9, (1). 5 - 14. Doi: 10.1046/j.1365 - 2850.2002.00393.x

Perry, J, Watkins, M, Gilbert, A, Rawlinson, J (2013) A Systematic review of service user involvement in interpersonal skills training of mental health students, Journal of psychiatric and mental health nursing, 20, 525-540. https://doi.org/10.1111/j.1365-2850.2012.01955.x

Sandvik, A-H., Eriksson, K. \& Hilli, Y. (2014). Becoming a caring nurse - A Nordic study on students, learning and development in clinical education. Nurse education in practice 14(3), p 286 - 292. Doi: https://doi.org/10.1016/j.nepr.2013.11.001 
Scammell, J., Heaslip, V. \& Crowley, E. J., (2016). Service user involvement in preregistration general nurse education: a systematic review. Journal of Clinical Nursing. (1-2): pp 53-69. Epub 2015 Oct 30. https://doi.org/10.1111/jocn.13068

Sharif, F, \& Masoumi, S. (2005) A qualitative study of nursing student experiences of clinical practice. BMC Nursing. 20054:6 https://doi.org/10.1186/1472-6955-4-6

Seshan, V., Ramasubramanium, S., Noronha, J. A., \& Muliira, R. (2010). Quality clinical learning environment. International Journal of Nursing Education, 3(1), 86-87.

Stockhausen, L.J. (2005). Learning to become a nurse: Students' reflections on their clinical experiences. Australian Journal of Advanced Nursing, 22, (3). 8 - 14.

Stockhausen, L.J. (2009). The patient as experience broker in clinical learning. Nurse Education in Practice, 9, (3). 184 - 189. Doi: https://doi.org/10.1016/j.nepr.2008.06.006

Suikkala, A., \& Leino-Kilpi, H. (2005). Nursing student - patient relationship. Experiences of students and patients, Nurse education Today. 25, (5). 344 - 354). Doi: https://doi.org/10.1016/j.nedt.2005.03.001

Suikkala, A., \& Leino-Kilpi, H. (2008). Nursing student - patient relationships. A descriptive study of students and patients views. International Journal of Nursing Education Scholarship, 5, (1). 1 - 12. Doi: https://doi.org/10.2202/1548-923X.1457

Towle, A., Bainbridge, L., Godolphin, W., Katz, A., Kline, C., Lown, B. \& Thistlethwaite, J. (2010). Active patient involvement in the education of health professionals. Medical Education, 44(1), 64. Doi: https://doi.org/10.1111/j.1365$\underline{2923.2009 .03530 . x}$

Towle, A., \& Godolphin, W. (2011). A meeting of experts: the emerging roles of nonprofessionals in the education of health professionals, Teaching in Higher Education, $\quad 16, \quad 5(), \quad 495-504 . \quad$ Doi: http://dx.doi.org/10.1080/13562517.2011.570442

Walker, S., Dwyer, T., Moxham, L. \& Sander, T. (2012). Facilitator versus preceptor. Which offers the best support to undergraduate nursing students? Nurse Education Today, 33 (5). 530 - 535. Doi: https://doi.org/10.1016/j.nedt.2011.12.005 